\title{
Characterisation of Fatigue Crack Growth in Silicone for Deap Technology
}

Thorup, Thor

Published in:

Proceedings of International Mechanical Engineering Congress \& Exposition

Link to article, DOI:

10.1115/IMECE2012-87238

Publication date:

2012

Document Version

Publisher's PDF, also known as Version of record

Link back to DTU Orbit

Citation (APA):

Thorup, T. (2012). Characterisation of Fatigue Crack Growth in Silicone for Deap Technology. In Proceedings of International Mechanical Engineering Congress \& Exposition (Vol. 3, pp. 627-634). American Society of Mechanical Engineers. https://doi.org/10.1115/IMECE2012-87238

\section{General rights}

Copyright and moral rights for the publications made accessible in the public portal are retained by the authors and/or other copyright owners and it is a condition of accessing publications that users recognise and abide by the legal requirements associated with these rights.

- Users may download and print one copy of any publication from the public portal for the purpose of private study or research.

- You may not further distribute the material or use it for any profit-making activity or commercial gain

- You may freely distribute the URL identifying the publication in the public portal

If you believe that this document breaches copyright please contact us providing details, and we will remove access to the work immediately and investigate your claim. 
IMECE2012-87238

\title{
CHARACTERISATION OF FATIGUE CRACK GROWTH IN SILICONE FOR DEAP TECHNOLOGY
}

\author{
Thor Thorup \\ Department of Mechanical Engineering \\ The Technical University of Denmark \\ Lyngby, Denmark \\ Email: s082866@student.dtu.dk
}

\begin{abstract}
In this paper, the fatigue crack growth characteristics of Elastosil ${ }^{\circledR}$ RT 625 are determined by performing fatigue crack experiments based on ISO 27727. Elastosil ${ }^{\circledR}$ RT 625 is a silicone rubber used by Danfoss PolyPower A/S as the dielectric material in their DEAP elements.

Cracks were characterised by a large amount of crack tip roughening, and a crack pattern that oscillated around the mean crack propagation direction. The amount of deviation from the expected crack path was proportional to the strain-level in the test. Despite the rough oscillating crack appearance, a linear relationship between the crack length and the amount of cycles was obtained. When plotting the crack growth per cycle against the applied load, the existence of a power law domain which can be described by Paris' Law was observed. The silicone rubber had a significantly lower $\beta$ exponent than a large range of other rubbers.
\end{abstract}

\section{INTRODUCTION}

Danfoss PolyPower A/S produce DEAP elements for a wide number of applications, ranging from energy harvesting to sensor applications. Most of the DEAP components under development are subjected to cyclic loading. In order to ensure reliable operation, it is of major importance to understand the fatigure properties of the dielectric material which makes up most of the DEAP. In this paper, the fatigue crack growth characteristics of the silicone rubber Elastosil ${ }^{\circledR}$ RT 625 , are found by performing fatigue crack experiments with pure shear test pieces, based on
ISO 27727. In the literature, the fatigue crack properties of silicone are not well described, and therefore this work wishes to contribute to the knowledge of the crack mechanisms in silicone rubber.

\section{FRACTURE MECHANICS}

Fracture mechanics is the study of the strength of materials that contain pre-existing flaws. Fracture in bodies is always initiated from an imperfection present in the body. An imperfection may arise from the manufacturing process, mechanical wear, or due to the initiation of a small crack at a large stress concentration. From these imperfections, cracks may grow when load is applied. The initial crack growth is typically slow at first, until it reaches a critical size where gross fracture occurs [1]. The crack growth characteristics of a material are therefore essential in order to determine its strength. According to Lake \& Thomas, the fracture mechanics approach is the main method which should be used for rubbers [1].

When an elastic body is strained, elastic energy is stored in a body. If the body contains a crack, the elastic energy within the body can be used to further propagate the crack. The energy necessary to propagate a crack is known as the strain energy release rate or the tear energy. The strain energy release rate is defined as the derivative of the stored elastic energy minus the work done by external forces $(\Pi=U-F)$ with respect to the half crack surface area (a crack has two surfaces). 


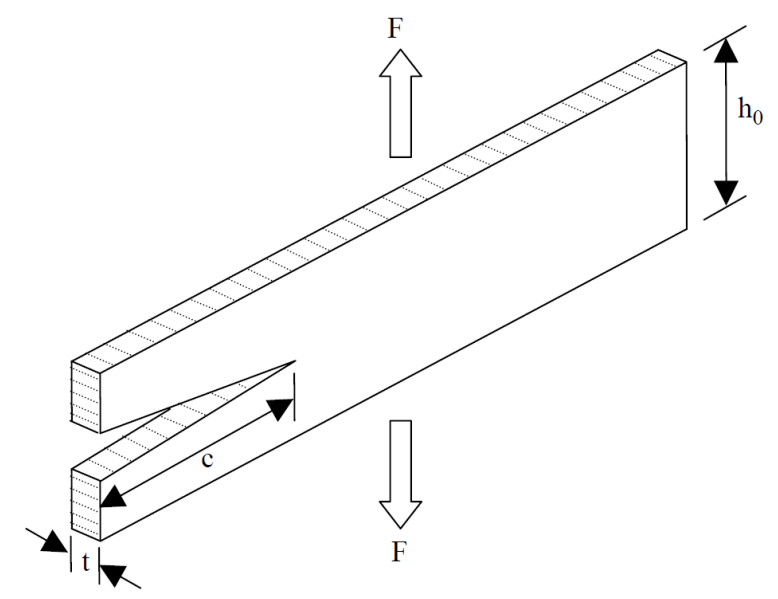

FIGURE 1. PURE SHEAR TEST PIECE [2]

$$
G=-\frac{\partial \Pi}{\partial A}
$$

$G$ can be determined by the area beneath the stress-strain curve, and geometrical factors. The critical strain energy release rate $G_{c}$, also known as the fracture toughness, is the energy release rate which causes gross fracture. It has been shown by experiment, and by analytical and numerical calculations that $G_{c}$ is independent of geometry and the loading condition, whether it be a constant displacement, or constant force loading. The temperature and the strain rate do influence $G_{c}$, although this effect is very material dependent [1].

In Fig. 1, the pure shear geometry is seen. For this geometry, the strain energy release rate is independent of the crack length, and is given as

$$
G_{c}=U_{c} h_{0}
$$

where $U_{c}$ is the strain energy density at fracture, and $h_{0}$ is the height of the test piece as shown in Fig. 1.

\section{Fatigue crack propagation}

Fatigue crack growth is a material characteristic that describes how gracks grow during cyclic loading. It is expressed as the crack growth per cycle $(d c / d N)$ as a function of the applied load. The applied load is usually represented by $\Delta G$. Since the loading can be determined by a prescribed displacement or stress, $\Delta G$ can be calculated, since the stress-strain curve of the material is known. Paris' Law is valid for many elastomers [1], and is given as

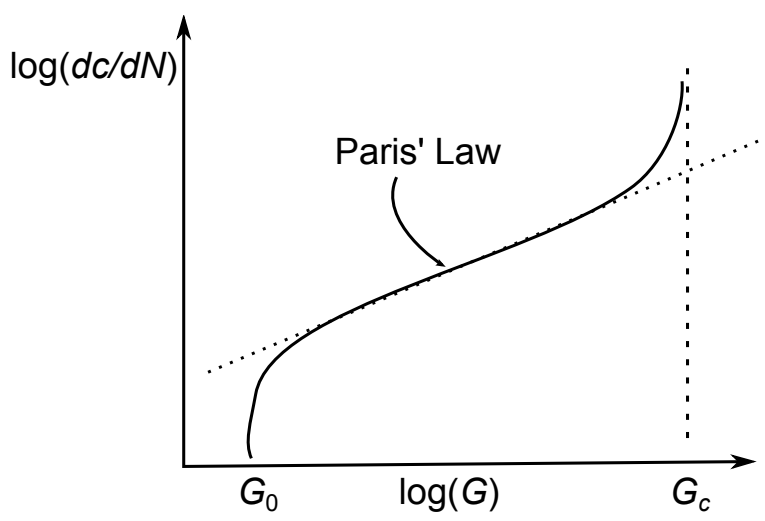

FIGURE 2. SCHEMATIC OF CRACK GROWTH CHARACTERISTIC CURVE

$$
\frac{d c}{d N}=B \Delta G^{\beta}
$$

where $B$ and $\beta$ are constants. $\beta$-values are typically between 2 to 6 for most rubber vulcanizates [1], though values have not been found in the literature for silicone. Often, only $G$ is represented in Paris' Law, since $\Delta G=G$ for fully relaxed conditions (zero pre-strain).

The total amount of cycles can be found by integrating Paris' Law from the initial crack size to the critical crack length. Fig. 2 shows a schematic of a log-log plot of the cyclic crack growth rate as a function of the maximum strain energy release rate (the maximum $G$ value for each given cycle). The curve is known as the crack growth characteristic of the material, since it is independent of geometry [1]. It is seen how there is a level of zero crack growth below $G_{0}$. As the applied load is increased, the crack growth enters a power law regime, where Paris' Law is valid. When the applied load approaches the critical strain energy release rate, there is a transition phase, where the crack growth rate increases rapidly, and gross fracture occurs.

For a large range of elastomers, $G_{0}$ takes on similar values of approximately $20-50 \mathrm{~J} / \mathrm{m}^{2}$ [1] [3]. This similarity suggests that the primary bond strength and the molecular structure of the vulcanizate are closely related to the $G_{0}$ value [1].

\section{EXPERIMENTS}

In order to characterise the fatigue properties of the silicone material, fatigue crack growth experiments were conducted in accordance with ISO 27727 [4], although there were deviations from the standard with regards to the amount of samples tested.

The pure shear geometry is used for the fatigue crack growth experiments as seen in Fig. 3, where $h_{0}=20 \mathrm{~mm}, L=200 \mathrm{~mm}$, 

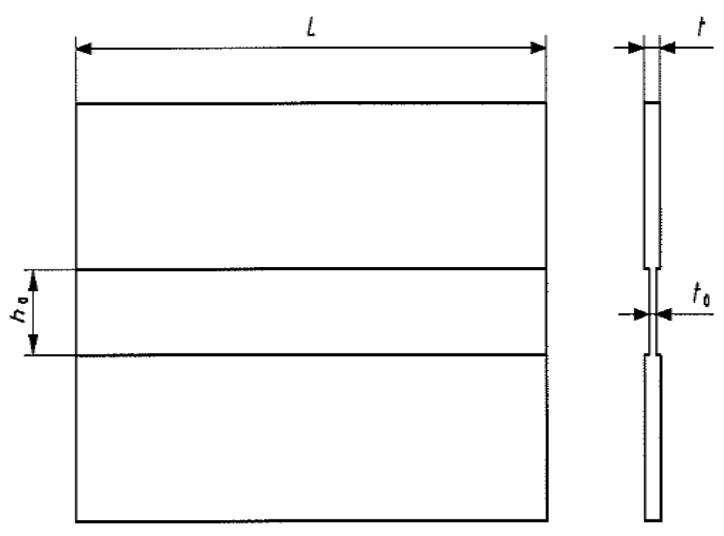

FIGURE 3. GEOMETRY OF THE PURE SHEAR TEST PIECE

$t=6 \mathrm{~mm}$, and $t_{0}=2 \mathrm{~mm}$. The geometry eliminates edge effects since it is much wider than it is tall. The two thick sections have a much larger cross sectional area than the thin section, thus they experience a much smaller stress and strain when subjected to loading and effectively de-couple the thin section from the thick sections.

\section{Manufacturing of test pieces}

The pure shear samples were manufactured in a custom aluminium mould. The liquid silicone was degassed before moulding to eliminate air bubbles in the mixture. The moulds where placed in an oven of $100^{\circ} \mathrm{C}$ for 1 hour, and were left overnigth, to ensure that the test pieces were fully vulcanised.

\section{Determination of $G(\varepsilon)$}

In order to plot the crack growth rate as a function of the strain energy release rate, the strain energy release rate had to be found as a function of the strain in the thin section of the pure shear test piece. This was done by integrating the stress strain curve of an uncut pure shear test piece. The stress strain curve of an uncut test piece is shown in Fig. 4.

Figure 5 shows the strain energy release rate as a function of the strain in the test piece. The critical strain energy release rate is equal to the $G$ value at break:

$$
G_{c}=38.4 \frac{\mathrm{kJ}}{\mathrm{m}^{2}}
$$

The strain energy can be fitted by a polynomial of third order, where $G(\varepsilon)$ is given as

$$
G(\varepsilon)=0.002 \varepsilon_{\%}^{3}-0.0331 \varepsilon_{\%}^{2}+37.152 \varepsilon_{\%}
$$

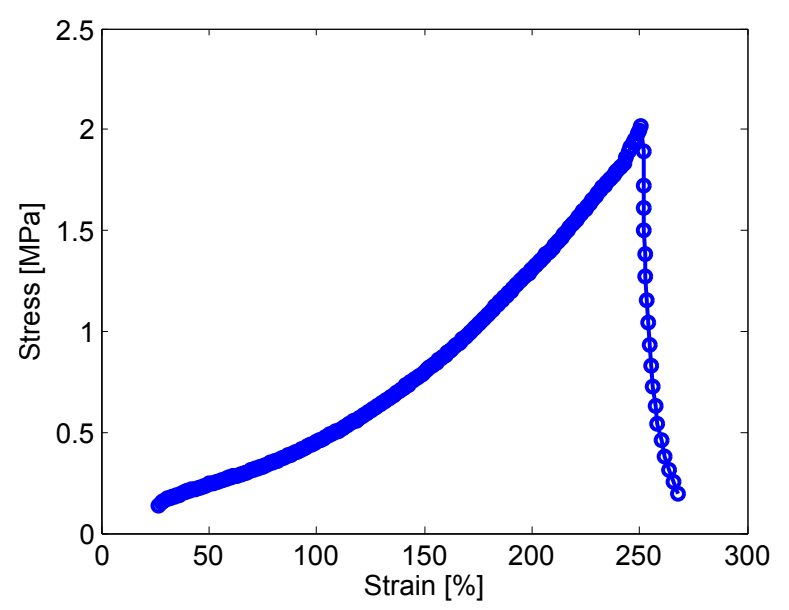

FIGURE 4. STRESS-STRAIN CURVE FOR THE PURE SHEAR TEST PIECE

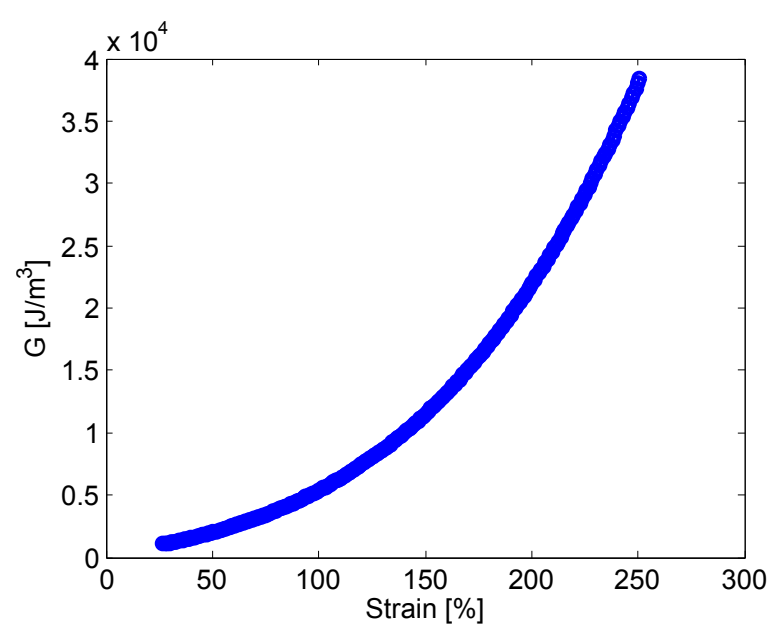

FIGURE 5. STRAIN ENERGY RELEASE RATE AS A FUNCTION OF THE STRAIN

where $\varepsilon \%$ is the strain in per cent.

\section{Fatigue crack growth}

The experimental setup is seen in Fig. 6. The cycling machine consisted of a rotational electrical motor connected to a sliding clamp by a connecting rod. The clamp attachment had guides which ensured stable linear motion of the clamp. The connecting rod could be placed in different slots in the flywheel, thus the engine stroke and thereby the strain in the test piece could be varied. All tests were conducted at a constant frequency of 3.06 $\mathrm{Hz}$ in order to eliminate the effect of frequency.

An initial cut of $30 \mathrm{~mm}$ was made in one side of the test piece with a scalpel, immediately before the test was conducted. The thick sections of the test pieces were clamped by aluminium 


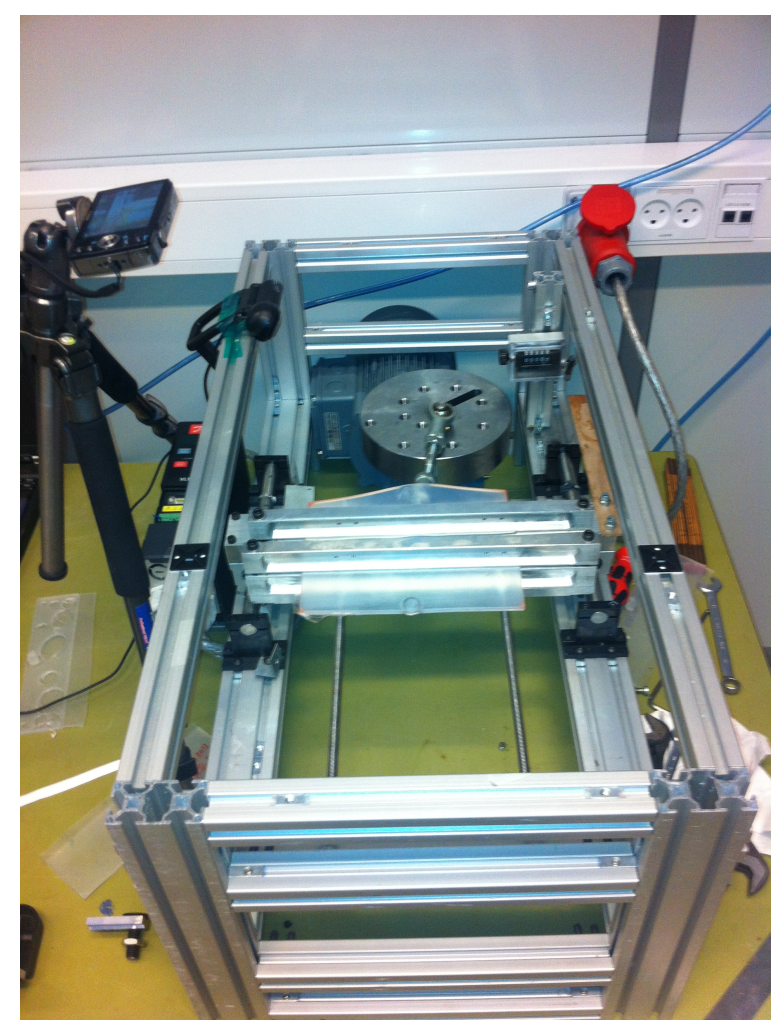

FIGURE 6. EXPERIMENTAL SETUP

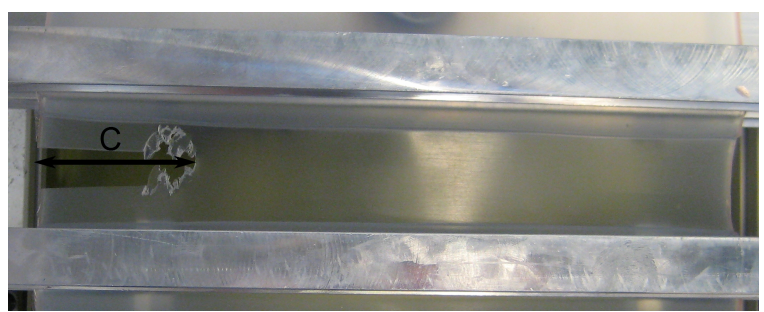

FIGURE 7. CRACK LENGTH DEFINITION

clamps, so that the distance between the clamps at zero strain was approximately $28 \mathrm{~mm}$. The crack length was measured with vernier callipers in intervals of 250 to 1000 cycles, depending on the strain level and test progression. Since the crack was not straight, the crack length reported is not equal to the actual crack length, as it was measured from the edge of the test piece to the furthest advancement of the crack, as illustrated in Fig. 7.

\section{Results}

In order to find the strain range of the test, tensile tests of two samples with a $30 \mathrm{~mm}$ cut were performed. The strains at break were $\varepsilon=99.4 \%$ and $\varepsilon=127 \%$, which indicates a variation in test pieces or test conditions. The setup is shown in Fig. 8. As seen in the figure, the clamping is not even, and there are quite

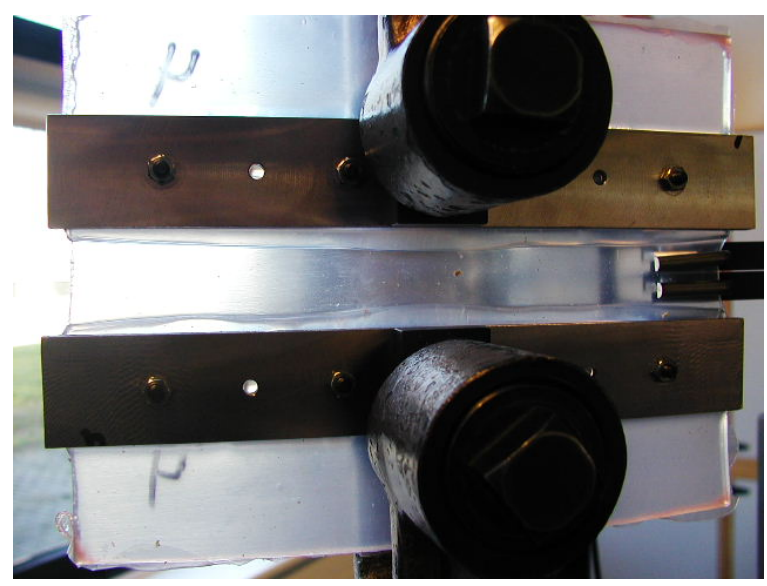

FIGURE 8. TENSILE TEST SETUP

large variations in the distance between the thicker parts of the test piece. This occured since it was necessary to clamp the test pieces very tightly in order to avoid sliding in the clamps, which occured for numerous test samples.

Fatigue experiments were conducted for 11 samples in total, at 11 different strain levels from $10 \%$ to $150 \%$ strain, where the tests started at the highest strain levels. The pre-strain was 0 in all cases (fully relaxed).

The crack length was measured as a function of the amount of cycles for all 11 test pieces. All samples were tested either until failure or until at least 20,000 cycles. An example of this measurement is seen in Fig. 9, which shows the crack growth characteristic at $50 \%$ strain. It is seen how the data can be represented by a straight line. The slope $d c / d N$ is the crack growth at the specific strain level, and thus $G$-level. Figure 10 shows the crack growth as a function of the strain energy release rate, and Fig. 11 shows the fatigue crack growth characteristic of the material in a log-log plot, which is how crack growth results are typically represented. Paris' Law (Eqn. 3) has been used to curve fit the data, and is plotted alongside the experimental results. The curve fit yields the constants $B$ and $\beta$, which are

$$
B=1.2 \cdot 10^{-7} \quad, \quad \beta=0.3
$$

The coefficient of determination is $R^{2}=0.75$, which is not a very good fit. However, the sample size is quite small, meaning that outliers have a large effect on this value. This will be discussed in the succeeding subsection.

Table 1 shows the crack growth exponents $\beta$ for different rubbers. It is seen that silicone has a significantly lower exponent than the other rubbers, meaning that it is more resistant to crack growth.

In Fig. 11 is seen that there is an area with a constant and significantly lower crack growth rate than in the power law area. 


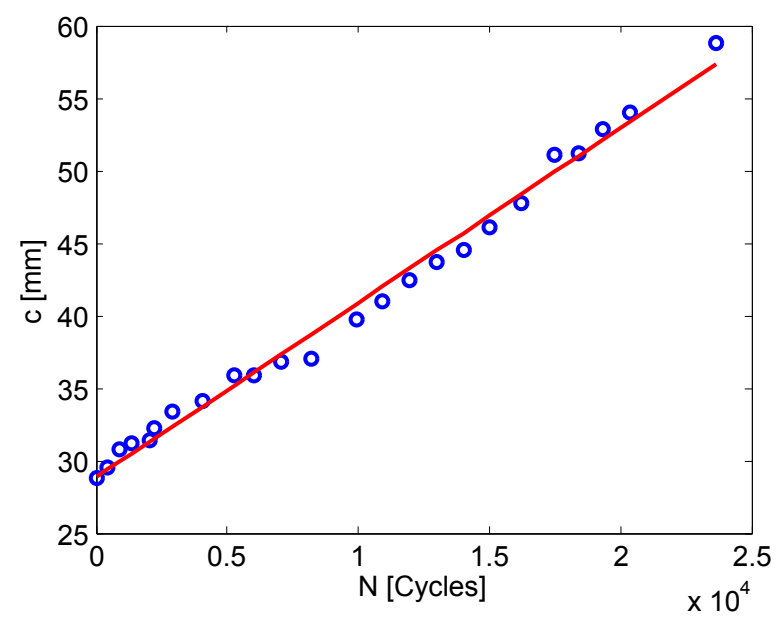

FIGURE 9. CRACK GROWTH CURVE AT $50 \%$ STRAIN

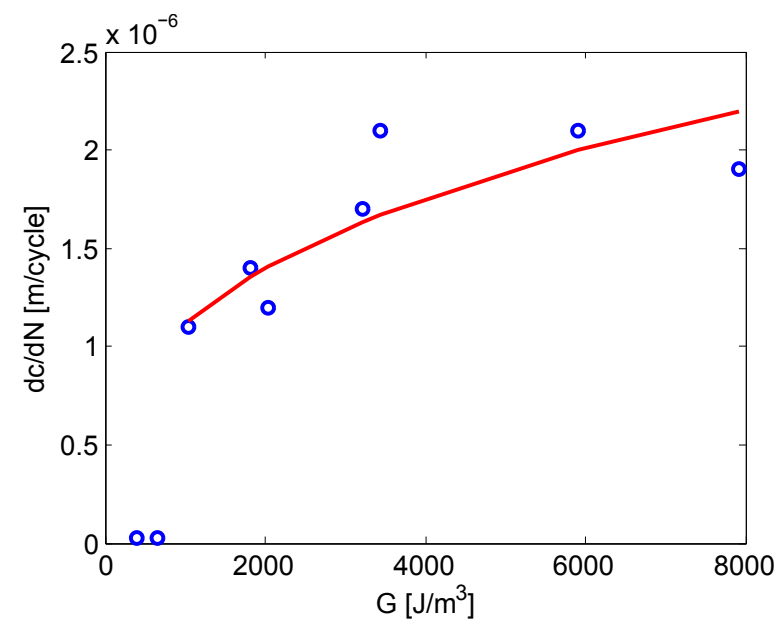

FIGURE 10. CRACK GROWTH AS A FUNCTION OF $G$

The crack growth in the constant domain is $30 \mathrm{~nm}$ per cycle, opposed to the approximately $1.5 \mu \mathrm{m}$ per cycle for the power law domain. The power law crack growth is approximately 50 times higher than the constant domain, indicating a clear rate transition as seen for many other materials such as natural rubber, SBR etc. [1]. Although the crack growth rate in the constant domain is relatively lower than for the power law domain, it cannot be considered to be negligible, thus $G_{0}$ must be found at even lower strain values than $10 \%$ strain. If it is assumed that $G_{0}$ is of similar values reported in [1] of approximately $50 \mathrm{~J} / \mathrm{m}^{2}$, then this corresponds to a strain level of approximately $1.4 \%$ strain (using Eqn. 5).

\section{Crack behaviour}

The typical crack behaviour is described in the following. As the crack started to propagate from the sharp tip cut by the

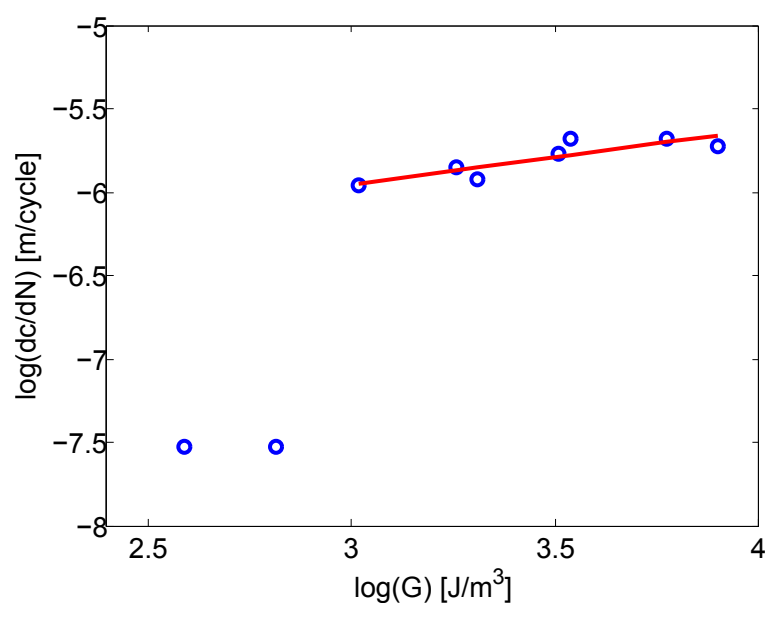

FIGURE 11. FATIGUE CRACK GROWTH PLOT

TABLE 1. $\beta$ EXPONENTS FOR DIFFERENT RUBBERS

\begin{tabular}{|c|c|}
\hline Rubber & $\beta$ \\
\hline NR & 2.0 \\
\hline IR & 2.0 \\
\hline SBR & 2.4 \\
\hline $\mathrm{BR}$ & 3.0 \\
\hline NBR & 2.8 \\
\hline $\mathrm{CR}$ & 3.4 \\
\hline EPDM & 3.2 \\
\hline Elastosil $^{\circledR}$ RT 625 & 0.3 \\
\hline
\end{tabular}

scalpel, the crack tip blunted and roughened, causing the crack tip to split into many small cracks, and also to deviate from the expected path (perpendicular to the tensile direction). The crack moved in an oscillating pattern for most of the crack propagation. In general, the amplitude or deviation from the mean crack path increased with increasing strain level. Figure 12 shows the difference in crack images for respectively $72 \%$ and $28 \%$ percent strain.

Figure 13 shows the fracture surface of both a smooth and a rough fracture surface. The images were taken with an optical microscope. The smooth surface was the result of abrupt crack propagation, where the crack suddenly advanced by $40 \mathrm{~mm}$ in a split second, while the rough surface is due to to slow fatigue crack propagation on the order of $2 \mu \mathrm{m}$ per cycle. It is clear that there is a large difference in the roughness of the crack surface. The rough image is taken from a side-on view, since a direct view of the crack surface is so bumpy that it is not possible to 

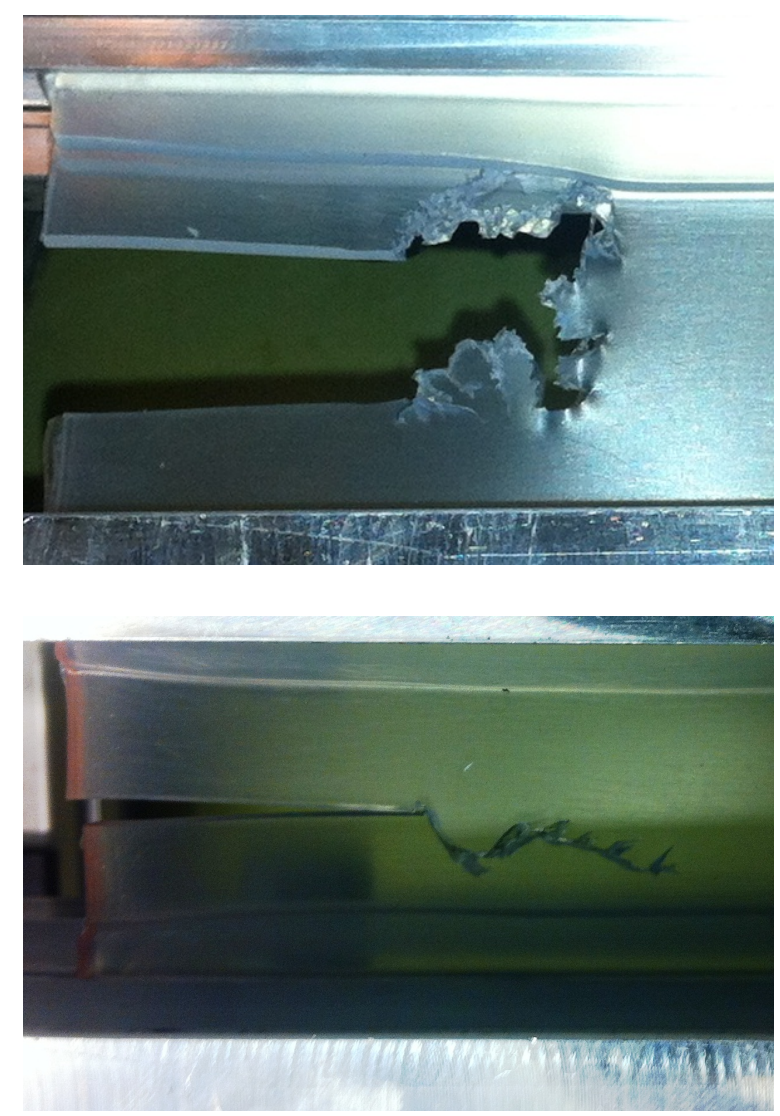

FIGURE 12. CRACK IMAGES FOR A) $72 \%$ STRAIN AND B) 28 $\%$ STRAIN

get a clear image. In the rough crack image, there seems to be parallel lines in the silicone surface. This is most likely due to the die which was polished with sandpaper, and in turn had small grooves in the aluminium surface.

The intriguing crack behaviour is most likely caused by the following factors:

Strain induced anisostropy As the samples are strained over many cycles, the molecular chains in the silicone align themselves in the tensile direction. Since the crack will travel in the path of least resistance, the crack deviates in the tensile direction along the dominating chain orientation, as described by Papadopoulus in [6].

Crack tip roughening due to filler content As described by Papadopoulos in [6], the presence of fillers increases the resistance to crack growth in the forward direction, but weakens the material in the transverse direction (tensile direction). Furthermore, interfacial debonding at large fillers cause deviations from the mean crack direction if many fillers are aligned
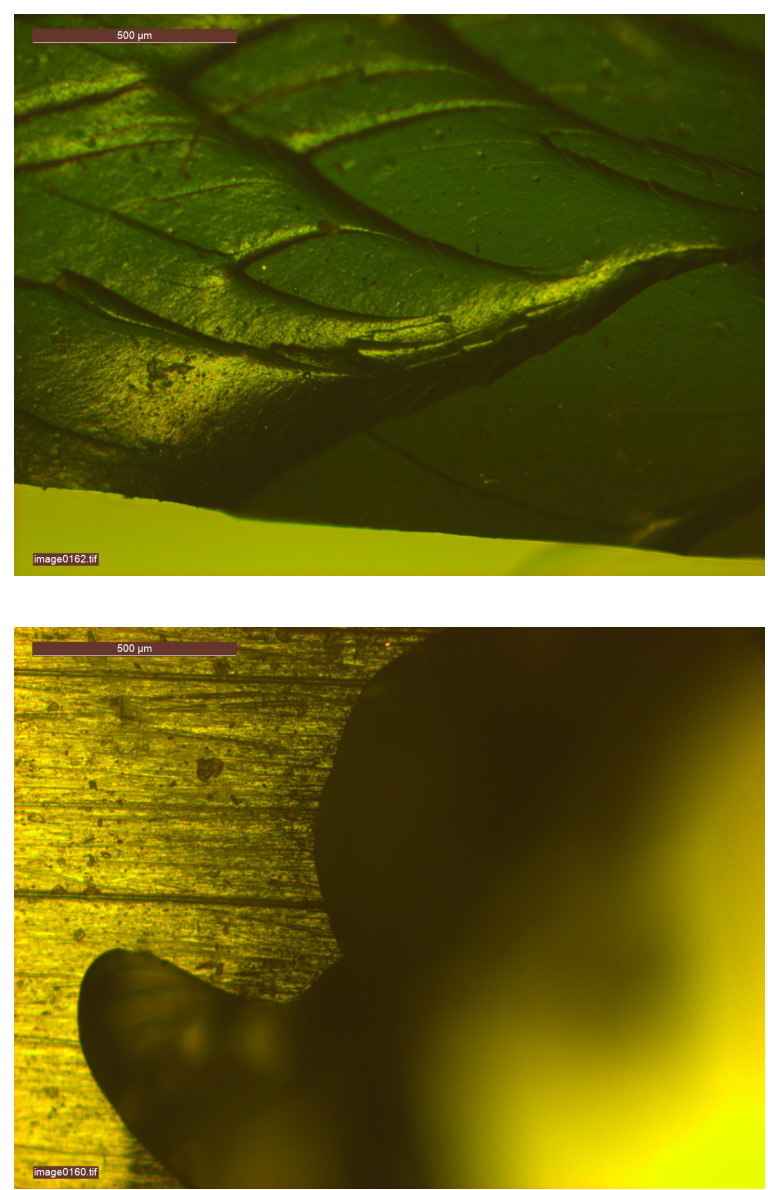

FIGURE 13. A) CRACK SURFACE FOR A FAST CRACK AND B) SLOW CRACK FROM ABOVE

in a specific direction. Fillers also tend to increase the scale of roughening, which is shown by Papadopoulos in [6].

Shear zones When viewed on a micro-scale, cracks in ductile metals grow in a zigzag pattern oriented $\pm 45^{\circ}$ from the crack propagation direction seen from a macro scale [7]. The maximum plastic strains occur $\pm 45^{\circ}$ to the crack direction, since this is where the shear stress in the material is at its maximum value. These zones of high shear stress are known as shear bands.

It is likely that something similar occurs in the silicone elastomer. The chain orientation and anisotropic behaviour complicates the overall explanation, but it is plausible that similar shear "zones" exist. Figure 14 shows how the crack propagates in an oscillating pattern, which is close to an angle of $\pm 45^{\circ}$. The oscillations are present at all strain values, where the amplitudes seem to be proportional to the strain level. 


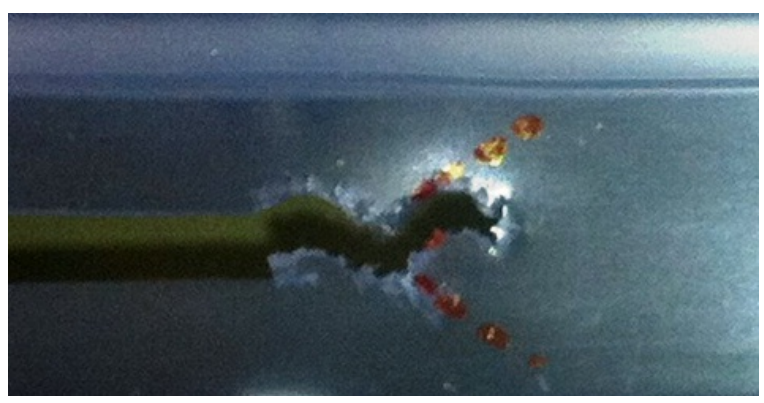

FIGURE 14. CRACK PROPAGATION AT $45 \%$ STRAIN

\section{Test piece variation and uncertainty}

In general, there was a good correlation between higher strain levels and higher crack growth rates. However, there were some test pieces that produced results which could indicate a difference in the mechanical properties of the test pieces.

All the samples were produced from the same silicone mixture, but they were manufactured over the course of one week, so there was inevitably a difference in the curing time needed. All test pieces were fully cured before testing. The mixture was not stirred before moulding, and this may have caused slightly different compositions, since the silicone is a mixture of four different components, which have slightly different densities.

Table 2 shows an overview of all the tested samples. It should be noted that samples 8 and 12 are tensile tests, where the strain indicated is the strain at break. Samples 9 and 10 show the most remarkable difference. At the same strain level, one sample fails instantly, while the other sample lasts almost 19,000 cycles.

There are several factors that can influence this large discrepancy. First of all, there could have been a difference in the silicone composition in the test pieces. This is however not the likely cause, since the two samples were manufactured consecutively from the same batch of silicone mixture.

There could have been a difference in the initial sharpness of the crack tip cut by the scalpel. If sample 10 had a much sharper crack tip than sample 9, perhaps this could have caused a much higher stress intensity at the crack tip. It is however dubious that the cut had such a large influence, since all samples were cut with the same scalpel, in the same manner.

Another cause of failure could have been the existence of a defect in the silicone material. This defect could have been the existence of small vulcanised silicone particles, which had not been removed from from the mould prior to casting. These particles could have created local stress concentrations within the material, causing small voids to form. If the amount of voids were substantial, coalescence of voids into a crack could occur, as described in [5].

As with all fatigue experiments, there is a statistical variation, which is best reduced by performing a large number of
TABLE 2. TEST SUMMARY

\begin{tabular}{|c|c|c|c|c|}
\hline Sample \# & Strain level & Cycles & $\begin{array}{l}\mathrm{dc} / \mathrm{dN} \\
{[\mathrm{m} / \text { cycle }]}\end{array}$ & Test type \\
\hline 1 & 0.10 & 19995 & $3.0 \cdot 10^{-8}$ & Cycle \\
\hline 2 & 0.18 & 46041 & $3.0 \cdot 10^{-8}$ & Cycle \\
\hline 3 & 0.28 & 21187 & $1.1 \cdot 10^{-6}$ & Cycle \\
\hline 4 & 0.46 & 19419 & $1.4 \cdot 10^{-6}$ & Cycle \\
\hline 5 & 0.50 & 23660 & $1.2 \cdot 10^{-6}$ & Cycle \\
\hline 6 & 0.72 & 20037 & $1.7 \cdot 10^{-6}$ & Cycle \\
\hline 7 & 0.75 & 19419 & $2.1 \cdot 10^{-6}$ & Cycle \\
\hline 8 & 0.99 & 0 & NA & Tensile \\
\hline 9 & 1.06 & 18802 & $2.1 \cdot 10^{-6}$ & Cycle \\
\hline 10 & 1.06 & 0 & NA & Cycle \\
\hline 11 & 1.24 & 15257 & $1.9 \cdot 10^{-6}$ & Cycle \\
\hline 12 & 1.28 & 0 & NA & Tensile \\
\hline 13 & 1.50 & 0 & NA & Cycle \\
\hline
\end{tabular}

experiments.

\section{Suggestions for future work}

To obtain a more accurate material representation, a much larger sample size should be used, along with the exact same silicone mixture for each sample. The issues regarding clamping of the test piece could be resolved by changing the sample dimensions, so that the thin section perhaps was 5-10 times thinner than the thick sections, instead of 3 times thinner. This would minimise the amount of strain in the thick sections, meaning that they could not be pulled out of the clamps over many cycles.

The effect of fillers could be investigated, if the mean sizes of filler particles were measured for different mixture compositions. The somewhat competing effects of large resistance to crack growth in the crack direction, and lower resistance to crack growth in the tensile direction should be quantified. Furthermore, it was shown by Zhong [5] that also the size distribution of particles have a large impact on crack growth behaviour. This was shown using the finite element method, but should be verified experimentally.

\section{CONCLUSION}

The aim of this work was to contribute to knowledge within the fatigue crack characteristics of Elastosil ${ }^{\circledR}$ RT 625 , which 
is a silicone rubber which is used by Danfoss PolyPower as the dielectric material in DEAP applications.

The strain energy release rate $G$ was found as a function of the strain by conducting tensile tests of pure shear test specimens. The critical strain energy release rate was found to be $G_{c}=38.4 \frac{\mathrm{kJ}}{\mathrm{m}^{2}}$. It was very problematic to actually conduct the tensile tests, since there occurred a considerable amount of sliding between the clamps and the test pieces.

Fatigue crack growth experiments were performed for pure shear test pieces. When Paris' Law was applied, material constants of $B=1.2 \cdot 10^{-7}$ and $\beta=0.3$ were obtained. The $\beta$ exponent is signifantly lower than for other rubbers, which indicates that silicone rubber is significantly more resistant to crack growth than for example NR and SBR.

Cracks propagated in a rough oscillating manner, while still maintaining a linear relationship between crack length and the number of cycles. The rough crack behaviour is most likely due to the high amount of anisotropy which results from high strain cycling, the existence of fillers within the silicone, and the potential existence of shear zones.

In order to obtain more accurate results, a much larger number of samples should be tested, with a stringent manufacturing and testing process. Furthermore, test pieces should be redesigned in order to mitigate clamping issues.

The effect of fillers on crack growth should be investigated. The somewhat competing effects of large resistance to crack growth in the crack direction, and lower resistance to crack growth in the tensile direction should be quantified.

\section{ACKNOWLEDGEMENT}

I would like to thank my superviser Professor Niels Henrik Mortensen from DTU Mechanical Engineering, Hans-Erik Kiil, Kim Lorenzen, Muhamed Benslimane and Rahimullah Sarban from Danfoss PolyPower A/S for assisting me and setting aside resources for this project.

\section{REFERENCES}

[1] Lake, G. J., and Thomas, A. G. Engineering with rubber How to design rubber components. Hansner Gardner.

[2] Kaang, S., Jin, Y. W., il Huh, Y., Lee, W.-J., and Im, W. B., 2005. "A test method to measure fatigue crack growth rate of rubbery materials". Polymer Testing.

[3] Gent, A. N., 1996. "Adhesion and strength of viscoelastic solids. is there a relationship between adhesion and bulk properties?". Polymer Science and Engineering.

[4] InTERnAtIONAL StANDARD, 2008. Rubber, vulcanized Measurement of fatigue crack growth rate.

[5] Zhong, X. A., and Knauss, W. G., 2000. "Effects of particle interaction and size variation on damage evolution in filled elastomers". Mechanics of Composite Materials and Structures, 7:1, 35-53.

[6] Papadopoulos, I. C., Thomas, A. G., and Busfield, J. J. C., 2007. "Rate transitions in the fatigue crack growth of elastomers". Journal of applied Polymer Science, Vol. 109.

[7] Anderson, T., 2005. Fracture mechanics: Fundamentals and applications. Taylor \& Francis. 